\title{
Proximate Composition, Antioxidant Capacity and Functional Properties of Breadnut Seed Flour (Artocarpus camansi)
}

\author{
Cherry Lyn M Alcon ${ }^{1, a, *}$, Aimee Sheree A Barrion ${ }^{1, b}$, Marie Faye Nguyen-Orca ${ }^{1, c}$ \\ ${ }^{I}$ Institute of Human Nutrition and Food, College of Human Ecology, University of the Philippines Los Baños, College, 4030 Laguna, Philippines \\ *Corresponding author

A R T I C L I N F O A B S T R A C T

\section{Research Article} \\ Received : 16/03/2021 \\ Accepted : 22/04/2021 \\ Breadnut is an indigenous fruit commonly found in Southeast Asia. The authors recognized the \\ potential of breadnut as a food source; thus, the study was set out to determine the proximate \\ composition and antioxidant activity of breadnut seed flour. The sample was found to contain $75 \%$ \\ carbohydrates, $9.07 \%$ fat, and $6.16 \%$ protein. Moreover, the flour made from breadnut yielded a \\ DPPH scavenging activity of $97.33 \%$, an indication of high antioxidant capacity. The flour was \\ blended with wheat flour to investigate its functional properties. It was observed that the 50:50 \\ breadnut seed flour and wheat flour showed potential in terms of water absorption capacity, fat \\ absorption capacity, emulsion capacity, and foaming ability. With the rising population and threat \\ to food and nutrition security, alternative sources must be explored. This study illustrated the \\ potential of breadnut as a source of energy and other nutrients. More so, its functional behavior as \\ an alternative or at least composite to wheat flour.
}

\section{Keywords: \\ Breadnut \\ Kamansi \\ Flour alternative \\ Flour composites \\ Proximate composition}

\section{(iD https://orcid.org/0000-0001-5198-8870} (iD) https://orcid.org/0000-0002-4997-6923
https://orcid.org/0000-0002-7639-470X

\section{Introduction}

Breadnut (Artocarpus camansi Blanco) is a fruit with large, dull-green to green yellow syncarp. This indigenous fruit, native to the Southeast Asia and Pacific region, is commonly prepared by boiling for vegetable stews or roasted like chestnuts (Ragone, 2006). Artocarpus species is known to exhibit medicinal characteristics that are attributed to its polyphenols, carotenoids, and anthocyanin contents. Jackfruit, a crop closely related to breadnut, is reported to have antioxidative, antiaging, hypotensive, and hypoglycemic properties (Mandave et al., 2018; Shahin et al., 2012). Breadnut also boasts its anti-inflammatory, antioxidant, antifungal, and antibacterial potential (Sikawar et al., 2014). Similarly, Nasution and his associates (2018) noted that the n-haxane crude extract from the peel of breadnut showed promise in reducing the blood glucose level in mice. The robust nutritional and health benefits of breadnut cannot be discounted. However, this crop remains underutilized. There are some studies that determined the possibility of breadnut as food source-as a meat substitute in making meatballs (Zamora, 2017), a nutrient bar (Colago et al., 2016), and cookies (Go et al., 2018). One probable reason for its low popularity to food processors is its short shelf-life with only two (2) days at ambient conditions after harvest (Adeleke and Abiodun, 2010). Therefore, one of the ways to increase its storage stability is by converting the seeds into flour. To date, there are limited studies done to ascertain the nutritive value of breadnut as well as its potential as an alternative flour. Thus, this research was done to evaluate the nutritional composition of breadnut seed flour. The study generally aims to determine the chemical composition and functional properties of breadnut seed flour.

\section{Materials and Methods}

\section{Experimental Protocol}

Breadnut fruit was processed to flour prior to proximate composition and antioxidant capacity characterization. Functional properties were then assessed considering its application as flour alternative or substitute by mixing it 
with wheat flour at four (4) different proportions $(100 \%$ breadnut, $75 \%, 50 \%$, and $25 \%$ ). Figure 1 illustrates the experimental protocol of the study.

\section{Sample Preparation}

Breadnut was collected in Roxas, Isabela, Philippines. Mature fruit was harvested, then seeds were collected and washed thoroughly. Seeds were then air-dried and deshelled. After which, the deshelled seeds were thinly sliced and dried in an air oven at $50^{\circ} \mathrm{C}$ to a moisture content of $2-3 \%$. The dried seeds were subjected to an electric grinder and pulverized at 40 mesh; thus, breadnut seed flour (BNSF) is produced. Figure 2 provides the summary of the flour preparation procedure.

\section{Chemical Analysis}

Moisture content was assessed following AOAC (2000) wherein the sample was dried at $105^{\circ} \mathrm{C}$ for 3 hours. Similarly, crude fat, crude protein, crude fiber, and total ash was measured as described by AOAC. Total carbohydrate was referred to as nitrogen free extract and was calculated by subtracting the proximate components to $100 \%$. The antioxidant capacity of BNSF was determined using the methods of Shimada et al. (1992) wherein the Dinitrophenyl picryl hydrazyl radical (DPPH) scavenging activity was evaluated.

\section{Functional Properties}

Four functional properties were assessed namely, water absorption capacity, fat absorption capacity, emulsion capacity, and foaming ability. Water absorption capacity was measured following the methods of the American Association of Cereal Chemists (AACC, 2007), while fat absorbance and emulsification capacity were done as described by $\mathrm{Yu}$ et al. (2007). On the other hand, foaming ability was determined as adopted from Sridaran et al. (2012).

\section{Results and Discussion}

\section{Proximate Composition of BSNF}

The proximate composition of breadnut seed flour (BNSF) was measured to assess its potential as a source of energy and nutrients. It was noted that the seed flour is primarily composed of carbohydrates $(75.39 \%)$. The results showed that the breadnut seed flour provide a substantial amount of fat, protein, carbohydrates, and fiber in the diet (Figure 3). One of the challenges of handling breadnut seed is its perishability, having a raw moisture content of 35\%-66\% (Rabeta and Syafiqah, 2016). Thus, moisture reduction is one of the measures done to increase its shelf-life, and processing breadnut seed into flour was able to lower the moisture content to $2.59 \%$. Consequently, low moisture content implies lower microbial activity, in turn, longer storage stability. To assess the capability of BNSF as food source, it was paralleled to the nutritional value of wheat flour with a total carbohydrate of $78.10 \%$, protein content of $14.7 \%$, fat content of $2.10 \%$, and fiber content of $2.10 \%$. This indicates that BNSF is comparable to that of wheat flour in terms of nutrient content, and may be used as an alternative or substitute to wheat flour.

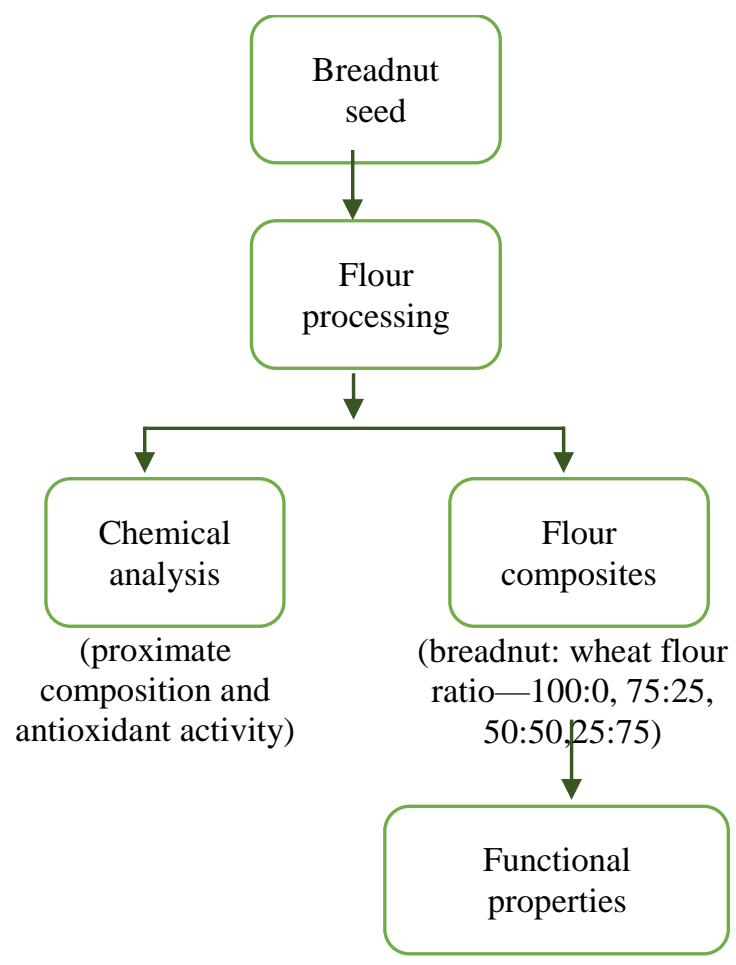

(water absorption capacity,

fat absorbance capacity, and emulsification capacity)

Figure 1. Experimental protocol of the study

\section{Antioxidant Capacity of BNSF}

Antioxidant capacity was estimated relative to the DPPH scavenging activity of the sample.

The collective capability of compounds presents to scavenge free radicals by DPPH reaction is referred to as the total antioxidant activity (Megalhes et al., 2006). BNSF exhibited high antioxidant capacity at $97.53 \%$. The DPPH radical has been accepted as a model compound for free radicals originating in lipids. It was postulated that the hydrogen donating ability of the compound present in the samples are responsible for the effect of antioxidants on DPPH radical scavenging (Conforti et al., 2006). The high DPPH scavenging activity indicates the high antioxidant capacity of the seed flour sample.

In a study done by Rabeta and Syafiqah (2016), the total phenolic content of the $A$. camansi was found in the highest quantity on the seeds with total phenolic contents (TPC) of $22.1 \mathrm{mg} \mathrm{GAE} / \mathrm{g}$ of seeds wet basis. Abu Bakar et al. (2009) reported that $A$. camansi has higher TPC than that of $A$. odoratissimus seed with $14.67 \mathrm{GAE} / \mathrm{g}$ of seeds. Phenolics are plant metabolites, they are reactive compounds that are known to neutralize free radicals which are associated with oxidative stress in the human body cells. The phenolic compounds also possess multiple biological properties and provide health benefits, that might be related to the antioxidant activity of plant samples since plants contain several phenolic compounds (Song, et al., 2010; Sevindik et al., 2017; Mohammed et al., 2019). Traditional medicine has been using plants as herbal remedies and supplemements, antioxidants used as supplements in bread was found to enhance the antioxidative capacity of blood plasma (Seidel et al., 2007; Mohammed et al., 2020). 


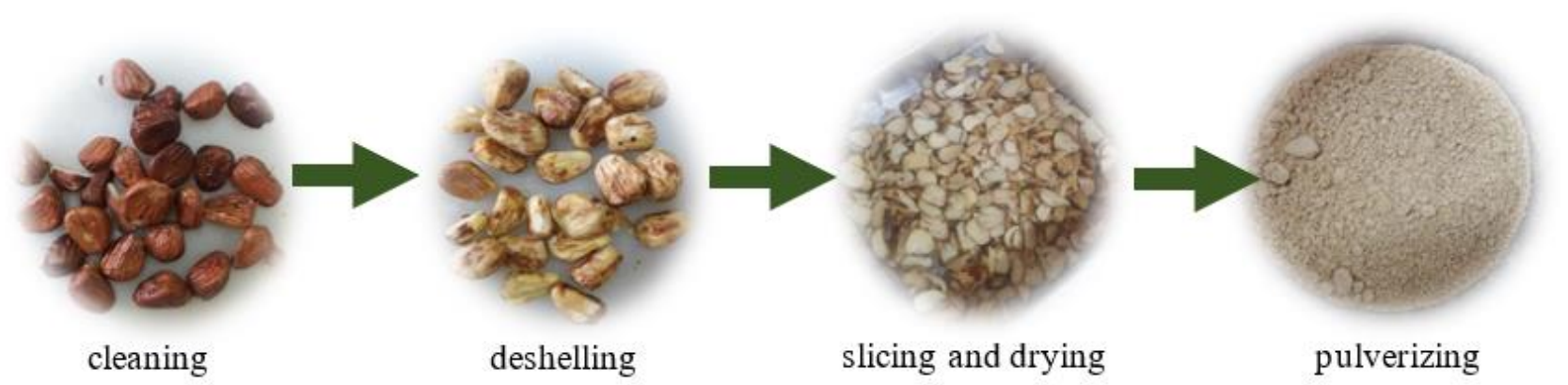

Figure 2. Illustration of the sample preparation process

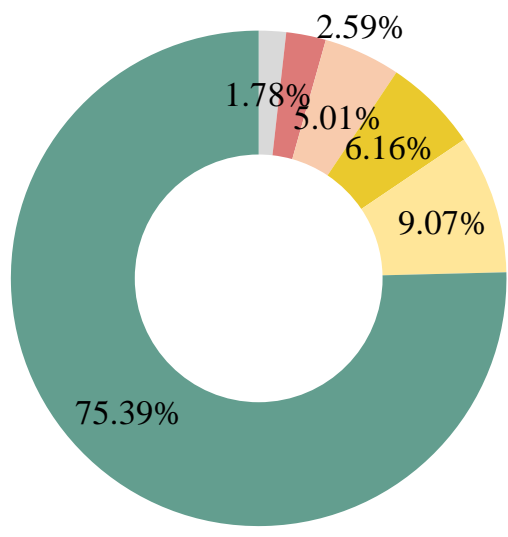

Crude fiber $\square$ Moisture content $\square$ Ash $\square$ Crude protein $\square$ Crude fat $\square$ Total Carbohydrate

Figure 3. Proximate composition of breadnut seed flour $(\%)$

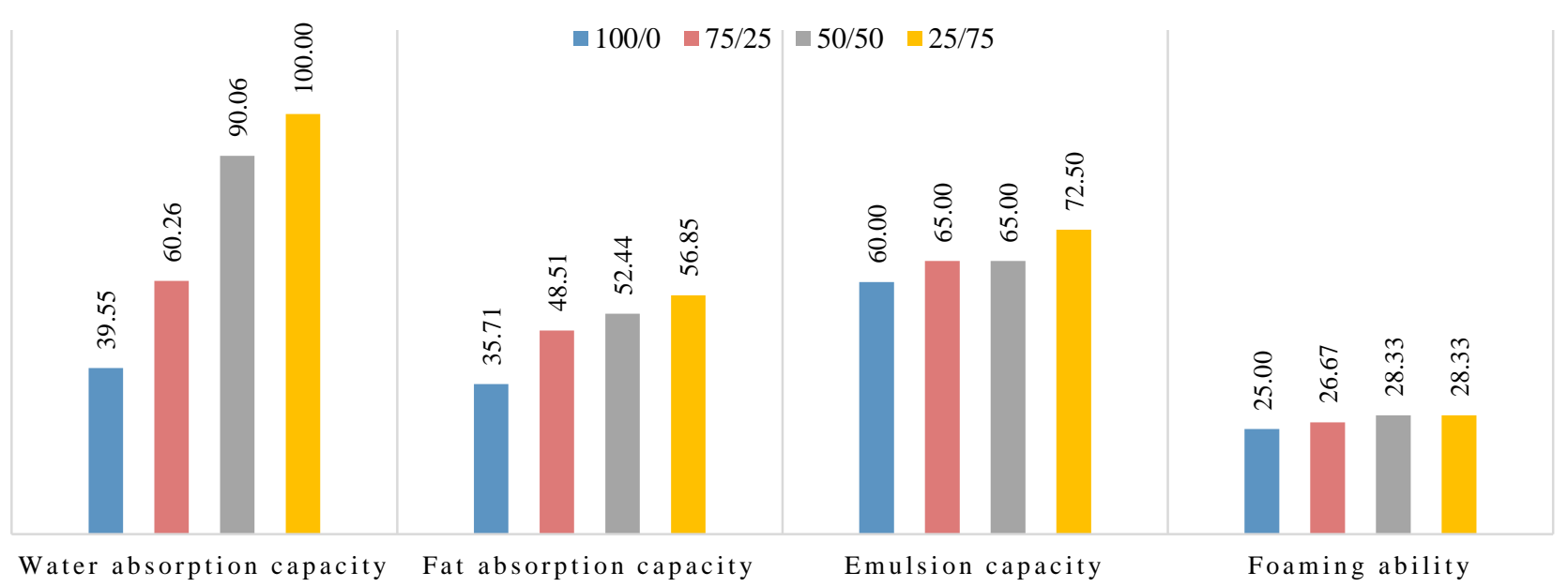

Figure 4. Functional properties of BNSF composites

\section{Functional Properties of BNSF Composites}

As the nutritive value and antioxidant activity of BNSF is already established, its behavior as a food ingredient was then observed. Four (4) treatments of BNSF and wheat composites (100\%BNSF, 75\% BNSF, 50\%BNSF, and $25 \%$ BNSF) were examined for their functional properties (Figure 4). Water absorption capacity and fat absorption capacity of the seed flours ranged from $39.55-100 \%$ and $35.71-56.85 \%$, respectively. The 25:75 ratio of BNSF and all-purpose flour exhibited the highest water absorption capacity at $100 \%$ It can be observed that the functional properties of the composites increases as the concentration of breadnut seed flour is decreased. The solubility values of the composite flours were greatly varied which means which may be attributed to the structure of the starch granules. It is suggested that the 25:75 flour ratio may be applicable in bakery products, specifically those that need hydration and improved dough properties.

Fat absorption capacity is influenced by the lipidbinding surface of hydrophobic amino acids therefore, the presence of both fat and protein yields higher fat absorption capacity (Noorfarahzilah et al., 2017). This indicates high fat absorption capacity is more likely to absorb and retain that the flour and may also facilitate fat soluble vitamin absorption. The foaming ability of the BNSF (100:0) is lower than wheat flour, which is considered as a standard for a good flour, with $40 \%$ foaming activity (Akubor, 2003). Similar to fat absorption capacity, foaming ability is 
related to the protein content of the flour. The type of protein present dictates the foamability of the productflexible protein molecules reduce the surface tension providing a good foam whereas globular proteins give low foamability (Yu et al., 2007). The crude protein content of BNSF may explain its high foaming ability of the composites. The amount of carbodydrate content can also affect the foamability of flour. With the breadnut seed flour having $75.39 \%$ of total carbohydrate, the hydrophilic component increases the viscosity of the solution and will also prevent gas bubbles to be destroyed (Poole,1989).

Results also showed that the breadnut seed flour has an emulsification capacity/ability of 60-70.5 volume of oil per gram sample. The emulsification ability of flour differs depending on the type, concentration and solubility of the proteins (Elkhalifa and Bernhardt, 2010). Moreover, the ability of the flour to be emulsified is affected by the fat content of the flour-for BNSF is $9.07 \%$. High fat content lowers protein interactions with other components such as carbohydrates. Overall, the flour with ratio concentration of 25:75 has the highest value for the water absorption capacity, fat absorption capacity and foaming ability. however, in developing this underutilized product it is important to have the breadnut seed flour as the main ingredient. Thus, overall, the composite with 50:50 blend ratio is considered acceptable due with comparable functional property results to the flour with a ratio of 25:75.

\section{Conclusion}

The prevalence of food and nutrition insecurity most especially in low-income countries is rising. For this reason, there is an increasing demand for alternative sources that match the nutritional contribution of common staples. This study recognized the potential of breadnut as source of energy and macronutrients. Utilization of breadnut as an ingredient may aid in the food supply as well as undernutrition problems. The results of this research noted that the proximate composition of breadnut seed flour is at par with that of all-purpose flour. Aside from its nutritional value, BNSF boasts high antioxidant capacity an indicator of potential health benefits. In realizing its use as a food ingredient, BNSF was blended with all-purpose wheat flour to determine its functional properties. It was noted that the 50:50 blend of BNSF and wheat flour exhibited properties that may be applied in food matrices. Therefore, BNSF provides a possibility of having substitutes that not only offers nutritional value but also health benefits. Further researches should be done in exploring the use of BNSF in different food products. Also, studies may be done to observe the health benefits of BNSF and its products.

\section{References}

Abu Bakar MF, Mohamed M, Rahmat A, Fry J. 2009. Phytochemicals and antioxidant activity of different parts of bambangan (Mangifera pajang) and tarap (Artocarpus odoratissimus). Food Chemistry, 113: $479-483$.

Adeleke RO, Abiodun OA. 2010. Nutritional Composition of Breadnut Seeds (Artocarpus camansi). African Journal of Agricultural Research, 5(11): 1273-1276.

Akubor PI, Isolokwu PC, Ugbane O, Onimawo IA. 2000. Proximate composition and functional properties of African breadfruit kernel and wheat flour blends. Food Research International, 33: 707-712.
Colago PAF, Alontaga HFC, Letrodo RD, Estrañero AB, Pajaron RN. 2016. Development of breadnut seeds (Artocarpus camansi) as bread products. BSc Thesis. College of Hotel and Restaurant Management, University of Cebu, Cebu, Philippines.

Conforti F, Vaccaro A, Loizzo MR, Statti GA, Autelitano G, Menichini F. 2006. Effects on free radicals and inhibition of alpha-amylase of Cardamine battagliae (Cruciferae), an apoendemic Calabrian (southern Italy) plant. Natural Products Research, 22(2): 101-107.

Elkhalifa AEO, Bernhardt R. 2010. Influence of grain germination on functional properties of sorghum flour. Food Chemistry, 12: 387-392.

Go MB, Velos SV, Minyamin AV, Bagsit RD, Pableo RG. 2013 Sensory evaluation, shelflife and nutritional composition of breadnut cookies. Topical Technology Journal, 16: 1-12.

Mandeve P, Bobade H, Patil S. 2018. Jackfruit seed flour: Processing technologies and applications. Review. International Journal of Agricultural Engineering, 11: 149-154.

Magalhaes LM, Segundo MA, Reis S, Lima JLFC. 2006. Automatic method for determination of total antioxidant capacity using 2, 2-diphenyl-1-picrylhydrazyl assay. Analytica Chimica Acta 558: 310 - 318 .

Mohammed FS, Karakaş M, Akgül H, Sevindik M. 2019. Medicinal properties of Allium calocephalum collected from Gara Mountain (Iraq). Fresen Environ Bull, 28(10): 74197426.

Mohammed FS, Şabik AE, Sevindik E, Pehlivan M, Sevindik M. 2020. Determination of Antioxidant and Oxidant Potentials of Thymbra spicata Collected from Duhok-Iraq. Turkish Journal of Agriculture-Food Science and Technology, 8(5): 1171-1173.

Nasution R, Fitrah CN, Helwati H, Muraniana, Arifin B, Cutchamzurni, Rizal Y, Marianne. 2018. Antidiabetes activities extract hexane from the peels of Artocarpus camansi blanco fruit. Asian Journal of Pharmaceutical and Clinical Research, 11(13):1-7.

Noorfarahzilah M, Mansoor AH, Hasmadi M. 2007. Proximate composition, mineral content and functional properties of Tarap (Artocarpus odoratissimus) seed flour. Food Research, 1(3): 89-96.

Poole S. 1989. The foam-enhancing properties of basic biopolymers. International Journal Food Science Technology, 24: 121-137.

Seidel C, Boehm V, Vogelsang H, Wagner A, Persin C, Glei M, Pool-Zobel BL, Jareihs G. 2007. Influence of prebiotics and antioxidants in bread on the immune system, antioxidative status and antioxidative capacity in male smokers and nonsmokers. British Journal of Nutrition, 97: 349-356.

Sevindik M, Akgul H, Pehlivan M, Selamoglu Z. 2017. Determination of therapeutic potential of Mentha longifolia ssp. longifolia. Fresen Environ Bull, 26(7): 4757-4763.

Shahin N, Alam S, Ali M. 2012. Pharmacognostical Standardization and Antidiabetic Activity of Artocarpus heterophyllus Lesves. International Journal of Drug Development and Research, 4(1): 346-352.

Sikawar MS, Hui BJ, Subramaniam K, Valeisamy BD, Yean LK, Balaki K. 2014. A review on Artocarpus altilis (Parkinson) Fosberg (breadfruit). Journal of Applied Pharmaceutical Science, 4(08): 91-98.

Song FL, Gan RY, Zang Y, Xiao Q, Kuang L, Li HB. 2010. Total Phenolic contents and antioxidant capacities of selected Chinese Medicinal Plants. International Journal of Molecular Sciences, 11(6): 2362-2372.

Sridaran A, Karim AA, Bhat R. 2012. Pithecellobium jiringa legume flour for potential food applications: Studies on their physico-chemical and functional properties. Food Chemistry, 130(3): 528- 535.

Rabeta MS, Syafiqah MJ. 2016. Proximate composition, mineral and total phenolic contents, and scavenging activity of breadfruit (Artocarpus camansi). Journal of Tropical Agriculture and Food Science, 44: 1-7. 
Ragone, D. 2006. Artocarpus camansi (Breadnut), ver.2. 1. In: Species profiles for pacific island agroforestry, (Elevitch, C.R., ed.), p. 1 - 11 Holuala: Permanent Agriculture Resources (PAR)

Yu J, Ahmedna M, Goktepe I. 2007. Peanut protein concentrate: Production and functional properties as affected by processing. Food Chemistry, 103(1):121-129.
Zamora CM, Vasquez JLB, Ebison MACV, Sibucao MD. 2017. Utilization of Breadnut (Artocarpus camansi) as a Meat Replacement for Meatballs. DLSU Research Congress 2017. 20-22 June 2017. De La Salle University, Manila, Philippines. pp. 1-6. 